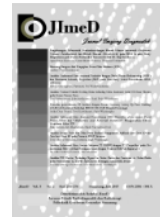

Jurnal Imejing Diagnostik (JImeD) 7 (2021) 106-110

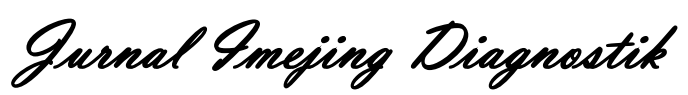

e-ISSN 2621-7457, p-ISSN 2356-301X

http://ejournal.poltekkessmg.ac.id/ojs/index.php/jimed/index

\title{
Analisa Faktor-Faktor Penyebab Kecemasan Pasien pada Pemeriksaan MRI (Magnetic Resonance Imaging)
}

\author{
Irma Rahmania \\ AKTEK Radiodiagnostik dan Radioterapi Patriot Bangsa Lampung, Indonesia \\ Corresponding Author: Irma Rahmania \\ e-mail: Rahmania2009@gmail.com
}

Received: July 29 ${ }^{\text {th }}, 2021$; Revised: July $31^{\text {st }}$, 2021; Accepted: July $31^{\text {st }}, 2021$

\begin{abstract}
Background: The existence of MRI (Magnetic Resonance Imaging) in every hospital is not widely known by the general public or patients, especially about the benefits and importance of MRI (Magnetic Resonance Imaging) for radiological supporting examinations. The problem with this examination revolves around its management, especially the indication that requires an MRI examination, the patient tends to have a perception with a little excessive concern that leads to the finding of abnormal examination results.

Methods: The research design used was descriptive qualitative with an observational analytic approach. The technique of determining the sample using a cross-sectional formula. With a sample size of 90 patients who underwent MRI examinations. Data obtained from literature study, observation, documentation, and questionnaires. Data analysis used bivariate with chi square method and multivariate with multiple regression test.
\end{abstract}

Result: Chi square and multivariate bivariate analysis with multiple regression test. The results showed that there was a significant relationship between age and education level variables.

Conclusion: Of the three variables tested, there are 2 factors that have a relationship with the patient's anxiety level, namely the age and education level of the patient.

Keyword: Anxiety; Patients; MRI Examination; Calculation.

\section{Pendahuluan}

Kecemasan merupakan respon normal dalam menghadapi stress, namun sebagian orang dapat mengalami kecemasan yang berlebihan sehingga mengalami kesulitan dalam mengatasinya (NIMH, 2013).

Jumlah penderita gangguan kecemasan mencapai 5\% dari jumlah penduduk dunia. Perbandingan penderita gangguan kecemasan pada wanita dan pria adalah 2 banding 1. Diperkirakan 2\%-4\% penduduk dunia pernah mengalami gangguan kecemasan (Sjahrir, 2008).

Penelitian di Uganda, Afrika menyatakan prevalensi gangguan kecemasan sebesar 26,6\% dengan wanita lebih tinggi dari pria, yaitu $29,7 \%$ pada wanita dan $23,1 \%$ pada pria (Catherine Abbo, et al., 2013). Wanita cenderung menggunakan emosinya untuk memecahkan suatu masalah. Mekanisme koping ini yang diduga menjadi penyebab mengapa prevalensi wanita lebih tinggi dari pria (McLean, C.P., Emily R. A., 2009). Penelitian di Asia didapatkan prevalensi gangguan kecemasan selama satu tahun berkisar antara 3,4\% sampai 8,6\% (Stein, 2009). Penelitian di Indonesia didapatkan prevalensi gangguan kecemasan $14 \%$ (Hidayat, 2010).

Tingkat pendidikan mempunyai hubungan dengan tingkat kecemasan seseorang. Berdasarkan hasil penelitian yang dilakukan oleh Sholichah dan Anjarwati (2014) semakin tinggi tingkat pendidikan wanita usia 40-50 tahun dalam menghadapi menopause maka semakin rendah tingkat kecemasannya begitu juga sebaliknya semakin rendah tingkat pendidikan wanita usia 40-50 tahun dalam menghadapi menopause maka semakin tinggi tingkat kecemasannya. Pendidikan merupakan sarana bagi individu agar nantinya mendapat pemahamahaman terkait kesadaran kesehatan. Semakin tinggi tingkat pendidikan maka akan semakin mudah seseorang menerima hal yang baru dan akan mudah menyesuaikan diri (Notoatmodjo, 2014). Selain Jenis kelamin dan tingkat pendidikan seseorang, umur juga memiliki hubungan dengan tingkat kecemasan seseorang. Angka kejadian kecemasan di Amerika 28\% atau lebih disebabkan oleh umur juga. Usia yang mengalami kecemasan 9- 
17 tahun sebesar 13\%, usia 18-54 tahun sebesar $116 \%$, dan usia 55 - lansia sebesar $11,4 \%$.

Hasil study pendahuluan di lapangan didapatkan wawancara yang dilakukan kepada beberapa pasien pada saat di ruangan MRI RSUD Dr.Hi. Abdul Moeloek Provinsi Lampung, beberapa pasien mengalami kecemasan karena baru pertama kali melakukan pemeriksaan MRI, belum mengetahui tentang apa yang dilakukan sebelum dan sesudah hasil pemeriksaan MRI ditemukan, banyak juga pasien yang merasa kurang nyaman saat melakukan pemeriksaan karena suara bising, dan ruangan yang gelap. Dan ada juga beberapa pasien yang merasa tidak cemas, karena sudah pernah menjalani pemeriksaan MRI sebelumnya, sudah mendapatkan penjelasan tentang MRI.

\section{Metode}

Jenis penelitian ini bersifat deskriptif kuantitatif dengan pendekatan analitik observasional. Penelitian ini dilaksanakan di Instalasi Radiologi RSUD Dr. Hi. Abdul Moeloek Provinsi Lampung pada bulan September-November 2020. Populasi dalam penelitian ini adalah pasien yang akan menjalani pemeriksaan MRI Pada bulan SeptemberNovember 2020. Dengan jumlah sampel yang digunakan sebanyak 90 orang pasien. Data diperoleh dengan cara Study Kepustakaan, Observasi dan Kuesioner. Pengolahan Data melalui 4 (empat) tahap, yaitu : Editing Data (Penyuntingan), Coding Data (Pengkodean), Data Entry / Processing Data (Pemrosesan), Cleaning Data (Pembersihan). Dengan menggunakan analisa univariat, bivariate metode chi square dan multivariate dan diolah secara deskriptif kemudian ditarik kesimpulan.Kata kunci yang digunakan Anxiety; Hospital; Patients, MRI Examination Calculations; SPSS. Bahan pustaka yang dipilih dengan kriteria ikklusi : bebahasa indomesia/inggris, diterbitkan pada tahun 2001 2020, artikel bukan berbayar (free acces full text) dan semua jenis bahan pustaka sepeti penelitian asli atau tinjauan sistematis.

\section{Hasil dan Pembahasan}

Hasil Analisa Bivariat metode chi square

Tabel 1. Hasil Analisa Bivariat jenis kelamin dengan tingkat kecemasan metode chi square

\begin{tabular}{|c|c|c|c|c|c|c|c|c|}
\hline \multirow{4}{*}{$\begin{array}{c}\text { Jenis } \\
\text { Kelamin }\end{array}$} & \multirow{4}{*}{\multicolumn{2}{|c|}{$\begin{array}{c}\text { Tidak } \\
\text { Cemas - } \\
\text { Cemas } \\
\text { Ringan }\end{array}$}} & \multirow{4}{*}{\multicolumn{2}{|c|}{$\begin{array}{c}\text { Cemas } \\
\text { Sedang- } \\
\text { Cemas } \\
\text { Ringan }\end{array}$}} & \multirow{4}{*}{\multicolumn{2}{|c|}{ Total }} & \multirow{4}{*}{$\begin{array}{c}\text { OR } \\
95 \% \\
\text { CI }\end{array}$} & \multirow{4}{*}{$\begin{array}{c}\text { p- } \\
\text { value }\end{array}$} \\
\hline & & & & & & & & \\
\hline & & & & & & & & \\
\hline & & & & & & & & \\
\hline Perempuan & 15 & $40,54 \%$ & 30 & $56,60 \%$ & 45 & $50 \%$ & & \\
\hline Laki-laki & 22 & $59,45 \%$ & 23 & $43,39 \%$ & 45 & $50 \%$ & 5,523 & 0,134 \\
\hline Jumlah & 37 & $41,10 \%$ & 53 & $58,90 \%$ & 90 & $100 \%$ & & \\
\hline
\end{tabular}

Berdasarkan tabel 1 diketahui bahwa sebanyak $66.7 \%$ responden dengan jenis kelamin Perempuan mengalami cemas sedang sampai cemas berat, sedangkan responden dengan jenis kelamin Lakilaki sebanyak $51.1 \%$ mengalami cemas sedang sampai cemas berat. Dengan begitu sebanyak $41.1 \%$ responden mengalami tidak cemas sampai cemas ringan.Hasil ujii statisktik diperoleh p-value sebesar 0.134 (lebih besar dari nilai alpha 0.05) yang berarti Ho ditolak sehingga disimpulkan tidak adanya hubungan yang bermakna antara jenis kelamin dengan tingkat kecemasan pasien saat menjalani pemeriksaan MRI. Dari hasil analisis juga diperoleh nilai $\mathrm{OR}=5.523(95 \%$ CI 3.22312.225) artinya jenis kelamin bukan merupakan faktor dari kecemasan pasien saat menjalani pemeriksaan MRI.

Tabel 2. Hasil Analisa Bivariat Umur dengan tingkat kecemasan metode chi square

\begin{tabular}{|c|c|c|c|c|c|c|c|c|}
\hline Umur & & $\begin{array}{l}\text { Tidak } \\
\text { Cemas- } \\
\text { Cemas } \\
\text { Ringan } \\
\end{array}$ & & $\begin{array}{l}\text { Cemas } \\
\text { edang- } \\
\text { Cemas } \\
\text { Ringan }\end{array}$ & & Total & $\begin{array}{c}\text { OR } \\
95 \% \\
\text { CI }\end{array}$ & $\begin{array}{c}\mathrm{p}- \\
\text { value }\end{array}$ \\
\hline Dewasa & 17 & $30,40 \%$ & 39 & $69,60 \%$ & 56 & $62,20 \%$ & 0,305 & 0,008 \\
\hline Remaja & 20 & $58,80 \%$ & 14 & $41,20 \%$ & 34 & $37,80 \%$ & & \\
\hline Jumlah & 37 & $41,10 \%$ & 53 & $58,90 \%$ & 90 & $100 \%$ & & \\
\hline
\end{tabular}

Berdasarkan tabel 2 diketahui bahwa ada sebanyak $69.6 \%$ responden dengan umur dewasa mengalami cemas sedang sampai cemas berat, sedangkan responden dengan umur remaja sebanyak $37.8 \%$ mengalami cemas sedang sampai cemas berat. Dengan begitu sebanyak $41.1 \%$ responden mengalami tidak cemas sampai cemas ringan.Hasil uji statisktik diperoleh p-value sebesar 0.008. Dari hasil analisis juga diperoleh nilai $\mathrm{OR}=$ 0.305 (95\% CI 0.125-0.743).

Tabel 3. Hasil Analisa Bivariat Tingkat Pendidikan dengan tingkat kecemasan metode chi square

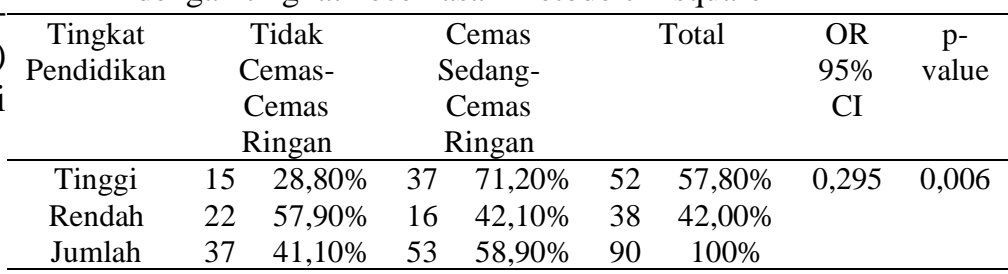

Berdasarkan tabel 3 diketahui bahwa ada sebanyak $71.2 \%$ responden dengan tingkat pendidikan tinggi mengalami cemas sedang sampai cemas berat, sedangkan responden dengan tingkat pendidikan rendah sebanyak $42.1 \%$ mengalami cemas sedang sampai cemas berat. Dengan begitu sebanyak $41.1 \%$ responden mengalami tidak cemas sampai cemas ringan.Hasil uji statisktik diperoleh 
p-value sebesar 0.006. Dari hasil analisis juga diperoleh nilai $\mathrm{OR}=0.295$ (95\% CI 0.122-0.711).

Berdasarkan hasil uji bivariat terdapat 2 variabel yang memiliki hubungan signifikan dengan kecemasan, variabel tersebut adalah tingkat pendidikan dan umur yang kemudian akan dianalisis secara multivariat. Analisis multivariat ditujukan untuk mengestimasi hubungan antara tingkat pendidikan dan umur terhadap kecemasan pada pemeriksaan MRI. Analisis yang digunakan adalah regresi linier berganda multivariat dengan tingkat kepercayaan 95\% (95\% CI).

Tabel 4. Hasil Analisa Multivariat Uji Regresi Linier

\begin{tabular}{ccccc} 
Model & $\mathrm{R}$ & R Square & $\begin{array}{c}\text { Adjusted } \\
\text { R Square }\end{array}$ & $\begin{array}{c}\text { Std. } \\
\text { Error of } \\
\text { the } \\
\text { Estimate }\end{array}$ \\
\hline 1 & 0,661 & 0,430 & 0,300 & 8,611 \\
\hline
\end{tabular}

Berdasarkan tabel 4 nilai $\mathrm{R}$ sebesar 0,661 menunjukan korelasi ganda (Umur dan Tingkat Pendidikan) dengan Tingkat Kecemasan. Nilai Adjusted $\mathrm{R}$ square sebesar 0,300 menunjukan besarnya peran kontribusi variabel Umur dan tingkat pendidikan mampu menjelaskan variabel kecemasan sebesar $30 \%$.

Tabel 5. Hasil Uji F

\begin{tabular}{ccccccc}
\hline & Model & $\begin{array}{c}\text { Sum of } \\
\text { Squares }\end{array}$ & df & $\begin{array}{c}\text { Mean } \\
\text { Square }\end{array}$ & F & Sig. \\
\hline 1 & Regression & 954,017 & 9 & 318,006 & 4,288 & 0,007 \\
& Residual & 6377,772 & 86 & 74,160 & & \\
& Total & 7331,789 & 89 & & & \\
\hline
\end{tabular}

Berdasarkan tabel 5 Hipotesis umur dan tingkat pendididkan secara bersama-sama berpengaruh terhadap kecemasan pasien. Nilai peobabilitas $\mathrm{F}$ (F-Hitung) dalam regresi berganda sebesar 0,007 <0,05 menjelaskan bahwa hipotesis (Ha) yang diajukan diterima yang berarti variabel umur dan tingkat pendidikan serta jenis kelamin pasien secara bersama-sama berpengaruh terhadap kecemasan.
Tabel 6. Hasil Uji Probabilitas t-Hitung

\begin{tabular}{|c|c|c|c|c|c|}
\hline \multirow[t]{2}{*}{ Model } & \multicolumn{2}{|c|}{$\begin{array}{c}\text { Unstandardized } \\
\text { Coefficients }\end{array}$} & \multirow{2}{*}{$\begin{array}{c}\text { Standarized } \\
\text { Coefficients } \\
\text { Beta }\end{array}$} & \multirow[t]{2}{*}{$\mathrm{T}$} & \multirow[t]{2}{*}{ Sig. } \\
\hline & B & $\begin{array}{l}\text { Std. } \\
\text { Error }\end{array}$ & & & \\
\hline (Constant) & 30,044 & 6,240 & & 4,815 & 0,000 \\
\hline Tingkat & 0,215 & 0,100 & 0,243 & 2,145 & 0,035 \\
\hline Pendidikan & & & & & \\
\hline Umur & 0,148 & 0,096 & 0,174 & 1,534 & 0,029 \\
\hline Jenis Kelamin & $-0,149$ & 0,247 & $-0,061$ & $-0,603$ & 0,548 \\
\hline
\end{tabular}

Berdasarkan tabel diatas maka hipotesis Ha1 dan Ha3 yaitu tingkat pendidikan dan umur memiliki pengaruh dengan kecemasan pasien dalam menghadapi pemeriksaan MRI di Instalasi Radiologi RSUD Dr. H. Abdul Moeloek Provinsi Lampung.

Dilihat dari nilai probabilitas t-hitung variabel tingkat pendidikan sebesar 0,035 menunjukan hipotesis alternative (Ha1) yang diajukan diterima, berarti tingkat pendidikan secara parsial berpengaruh terhadap kecemasan pasien dalam menghadapi pemeriksaan MRI, dan Nilai probabilitas t-hitung variabel umur sebesar 0,029 menunjukan hipotesis alternative (Ha3) yang diajukan diterima yang berarti umur secara parsial berpengaruh terhadap kecemasan pasien dalam menghadapi pemeriksaan MRI, serta Nilai probabilitas t-hitung variabel jenis kelamin sebesar 0,548 menunjukan hipotesa alternative ( $\mathrm{Ha} 2)$ yang diajukan tidak diterima yang berarti jenis kelamin secara parsial tidak berpengaruh terhadap kecemasan pasien dalam menghadapi pemeriksaan MRI.

\section{Simpulan}

Berdasarkan dari analisa bivariate dengan metode chi-square pada variabel jenis kelamin didapatkan nilai berupa $\mathrm{p}$ - value serta ood ratio yang menjelaskan hubungan jenis kelamin dengan kecemasan pasien dalam pemeriksaan MRI di Instalasi Radiologi RSUD Dr. H. Abdul Moeloek Provinsi Lampung, yaitu pasien dengan jenis kelamin perempuan memiliki tingkat kecemasan paling tinggi dibandingkan dengan jenis kelamin laki-laki.dikuatkan dengan Hasil uji statisktik diperoleh p-value sebesar 0.134 (lebih besar dari nilai alpha 0.05) yang berarti Ho ditolak sehingga disimpulkan tidak adanya hubungan yang bermakna antara jenis kelamin dengan tingkat kecemasan pasien saat menjalani pemeriksaan MRI. Dari hasil analisis juga diperoleh nilai $\mathrm{OR}=5.523(95 \% \mathrm{CI}$ 3.223-12.225) artinya jenis kelamin bukan merupakan faktor dari kecemasan pasien saat menjalani pemeriksaan MRI. 
Sementara pada variabel tingkat pendidikan didapatkan bahwa pasien tingkat pendidikan lebih tinggi memiliki kecemasan paling tinggi dibandingkan dengan pasien tingkat pendidikan yang rendah. Hasil uji statisktik diperoleh p-value sebesar 0.006 (lebih kecil dari nilai alpha 0.05 ) yang berarti Ha diterima sehingga disimpulkan adanya hubungan yang bermakna antara tingkat pendidikan dengan tingkat kecemasan pasien saat menjalani pemeriksaan MRI. Dari hasil analisis juga diperoleh nilai $\mathrm{OR}=0.295$ (95\% CI 0.122-0.711) artinya tingkat pendidikan merupakan faktor dari kecemasan pasien saat menjalani pemeriksaan MRI. sedangkan pada variabel umur didapatkan bahwa pasien dengan umur remaja memiliki kecemasan paling tinggi dibandingkan dengan pasien umur dewasa. hasil uji statisktik diperoleh p-value sebesar 0.008 (lebih kecil dari nilai alpha 0.05) yang berarti $\mathrm{Ha}$ diterima sehingga disimpulkan adanya hubungan yang bermakna antara umur dengan tingkat kecemasan pasien saat menjalani pemeriksaan MRI. dari hasil analisis juga diperoleh nilai $\mathrm{OR}=0.305$ (95\% CI 0.125-0.743) artinya umur merupakan faktor dari kecemasan pasien saat menjalani pemeriksaan MRI.

\section{Daftar Pustaka}

Alimul Hidayat A.A,. 2010 Metode Penelitian Kesehatan Paradigma Kuantitatif. Jakarta : Heath Books.

Ah. Yusuf, Rizky Fitryasari P.K., Hanik Endang Nihayati. 2015 Keperawatan Kesehatan Jiwa. Jakarta : Heath Books.

Bushberg, J.T, Seibert, J.A., Leidholdt, E.M.J., and Boone, J.M. 2013 The Essential Physics of Medical Imaging $2^{\text {nd }} E d$. Philadelphia. Lippincot Williams and Wilkins Catherine, 2013. Prevalence, Comorbidity and Predictions of Anxiety disorders in Children and Adolescen. Rural North-Eastern Uganda. Child and Adolescent Psychiatry and Mental Health.

Fortinas \& Worret. 2003.Psychitiatric Mental Health Nursing, third edition. St, Louis : Mosby.

Hawari, Dadang. 2004. Psikiater Manajemen Stress,Cemas dan Depresi. Jakarta : Fakultas Kedokteran Universitas Indonesia. McLean, C. P., Emily R. A., 2009 Brave Men and Timid Women a Review of The Gender
Differences in Fear and Anxiety. Clin Psych.

Miguel, 2012 The Effects of Anxiety on Cognitive Performance. Phd Thesis.

Notoadmodjo, S. 2005. Metodologi Penelitian Kesehatan. Jakarta : Rineka Cipta.

Notoatmodjo, S. 2010. Metodologi Peneitian Kesehatan. Jakarta : Rineka Cipta.

Notoatmodjo, S. 2014.Ilmu Perilaku Kesehatan, Jakarta : Rineka Cipta.

Notoatmojo, Soekidjo. 2014. Metodologi Penelitian Kesehatan. Jakarta : Rineka Cipta.

Notosiswoyo M. 2004, Pemanfaatan Magnetic Resonance Imaging (MRI) Sebagai Sarana Diagnose Pasien. Media Litbang Kesehatan no.3, vol XIV.

Rasad, Sjariar. 2014, Radiologi Diagnostik. Jakarta : Penerbit Balai FK UI.

Santoso, Singgih. 2014, Statistik Multivariat Edisi Revisi. Jakarta : PT Elex Media Komputindo.

Rasad, Sjariar. 2020, Radiologi Diagnostik. Edisi 2. Jakarta : FKUI.

Sjahrir, Hasan. 2008, Nyeri Kepala dan Vertigo. Yogyakarta : Pustaka Cendekia Press.

Sholichah, N., Anjarwati, R. 2014, Hubungan Tingkat Pendidikan dengan Tingkat Kecemasan Wanita Usia 40-50 Tahun dalam Menghadapi Menopause.

Stein, S.J dan Book, H.E. 2004 Ledakan EQ. Limabelas Prinsip Dasar Kecerdasan Emosi Meraih Sukses (Terjemahan Trinanda Riani Januarsari dan Yudhi Murtanto). Bandung: Kaiffa.

Stuart and Sundeen. 2007 Buku Saku Keperawatan Jiwa Edisi 5. Jakarta: EGC.

Stuart, GW. 2009 Buku Saku Keperawatan Jiwa, Edisi 5. Jakarta : EGC.

Sutardjo A. Wiramihardja. 2005 Psikologi Abnormal. Bandung.

Suliswati, 2005 Konsep Dasar Keperawatan Kesehatan Jiwa. Jakarta : EGC.

Wijaya, Tony. 2013 Analisa Data Penelitian Menggunkan SPSS. Ed:5. Yogyakarta. Universitas Atma Jaya.

NIMH (National Institute of Mental Health) Senior Health. Anxiety Disorders: Risk Factors and

Diagnosis. 
http://nihseniorhealth.gov/anxietydisorders

rriskfactorsandcauses/01.html. diakses

tanggal 26 Mei 2019 pkl. 23.30 WIB 